\title{
Uterine artery Doppler in first trimester in prediction of adverse pregnancy outcome in Dharmapuri district of Tamil Nadu
}

\author{
Bindu S.* \\ Department of Obstetrics and Gynecology, Government Dharmapuri Medical College, Dharmapuri, Tamil Nadu, India \\ Received: 25 August 2020 \\ Accepted: 10 September 2020 \\ *Correspondence: \\ Dr. Bindu S., \\ E-mail: arvindr84@gmail.com \\ Copyright: (C) the author(s), publisher and licensee Medip Academy. This is an open-access article distributed under \\ the terms of the Creative Commons Attribution Non-Commercial License, which permits unrestricted non-commercial \\ use, distribution, and reproduction in any medium, provided the original work is properly cited.
}

\begin{abstract}
Background: Pregnancies are complicated by hypertensive disorders of about 5-10\% and hemorrhage, sepsis, and fetal growth restriction constitute a triad contributing to maternal morbidity and mortality. Hypertensive disorders in pregnancy vary from mildly elevated blood pressure to severe hypertension with multi-organ dysfunction. The study aims to evaluate the first-trimester uterine artery Doppler in the prediction of the development of adverse pregnancy outcomes.

Methods: This prospective longitudinal observational was done in Dharmapuri Medical College and Hospital were selected for this study. Totally 150 pregnant women were included in the study. 75 were controls and 75 cases. The study period was from June 2018 to February 2019. Evaluating the optimal definition of abnormal first trimester.

Results: Previous obstetric history in the study population. In the study group $3 \%$ of bad obstetric history (BOH) present. In the case group, $5 \%$ has $\mathrm{BOH}$ due to 2 neonatal death and 2 term intrauterine device (IUD), uterine artery Doppler parameters to predict adverse pregnancy outcomes, and association of gestational hypertension in the study groups. In the control group, 1\%, and the case group 5\% of them had gestational hypertension. Out of 4, 3 had an average uterine artery Doppler more than 2.3 (maximum of 2.7) and 1 had single uterine artery Doppler abnormality. Conclusions: The study showed that first-trimester uterine artery Doppler with single and average uterine artery pulsatility index $(\mathrm{PI})>95$ th centile $(2.3)$ has a better screening value in my population. The overall performance of the first-trimester uterine artery Doppler in the prediction of adverse pregnancy outcomes is valuable.
\end{abstract}

Keywords: Uterine artery Doppler abnormality, Gestational Hypertension, First trimester

\section{INTRODUCTION}

Pregnancies are complicated by hypertensive disorders of about 5-10\% and along with hemorrhage, sepsis and fetal growth restriction constitute a triad contributing to maternal morbidity and mortality. ${ }^{1,2}$ Hypertensive disorders in pregnancy vary from mildly elevated blood pressure to severe hypertension with multi-organ dysfunction. Of these disorders the preeclampsia syndrome, either alone or superimposed on chronic hypertension and its associated maternal mortality is the most dangerous and it accounts for $16 \%$ and is preventable. ${ }^{3}$ The incidence of pre-eclampsia $(\mathrm{PE})$ varies between $8-10 \%$ of all pregnancies. In nulliparous women, the incidence of PE ranges between $2 \%$ and $7 \%$ (who conceive with assisted reproductive technology). This is responsible for 29,000 maternal deaths per year worldwide. $^{4,5}$ There is a 5 -fold increase in perinatal mortality in PE due to iatrogenic prematurity, respiratory distress syndrome, and neonatal intensive admission. ${ }^{6,7}$ Intensive maternal and fetal monitoring in such high-risk patients would lead to an earlier diagnosis of the clinical signs of the disease and the associated fetal growth restriction and avoid the development of serious complications such as placental abruption, eclampsia, Intrauterine death through such interventions as the administration of antihypertensive medication and early delivery. Modern antenatal care provision is focused on a 
risk-based approach to monitoring for adverse pregnancy outcomes such as PE, fetal growth restriction, placental abruption, stillbirth, and pregnancy outcome of baby. ${ }^{8}$ Early identification of the high-risk group for the development of adverse pregnancy outcomes is also important for future studies investigating the potential role of pharmacological interventions starting from the first trimester to improve placentation and reduce the prevalence of the disease. Several prophylactic therapies (anti-oxidant, vitamins, folic acid supplementation, and aspirin) have so far tried to prove its efficacy in the prevention of PE in healthy nulliparous groups. ${ }^{9}$ Antenatal outcome can be improved by early identification of PE by alerting the clinicians to the need of therapeutic prophylaxis and additional surveillance later in pregnancy, thus an increase in perinatal surveillance with a significant decline in maternal and fetal mortality and morbidity which is associated with $\mathrm{PE}$ and eclampsia. ${ }^{10}$ Impaired placentation with abnormal blood flow velocity and resistance in placental vessels is associated with PE and fetal growth restriction. The prediction of hypertensive disorders and associated adverse outcomes by ultrasonography plays an important role. ${ }^{11}$ Uterine artery Doppler waveform analysis has been extremely studied in the second trimester of pregnancy as a predictive marker for the late development of PE and fetal growth restriction. The use of Doppler interrogation of this vessel in the first trimester has gained momentum in recent years. ${ }^{12}$

\section{METHODS}

This prospective longitudinal observational was done in Dharmapuri Medical College and Hospital were selected for this study. A total of 150 pregnant women were included in the study, 75 were controls and 75 cases.

The study period was from June 2018 to February 2019. Evaluating the optimal definition of abnormal first trimester, it was found to be 11-13 weeks +6 days of gestation. In this visit, the women will have an ultrasonogram for the following reasons:

\section{Inclusion criteria}

All pregnant women attending antenatal check-up in PSG Institute of Medical Sciences and Research (PSG IMSR) between 11 to $<13$ weeks +6 days were included in the study.

\section{Exclusion criteria}

History of preeclampsia, chronic hypertension, twins, missed abortion, major fetal anomaly which is incompatible with life, and women not showing consent were excluded from the study.

\section{Statistical analysis}

The data are reported as the mean \pm standard deviation (SD) or the median, depending on their distribution. The differences in quantitative variables between groups were assessed using the unpaired t-test. A comparison between groups was made by the non-parametric Mann-Whitney test. The chi-square test was used to assess differences in categoric variables between groups. A p-value of $<0.05$ using a two-tailed test was taken as being of significance for all statistical tests. All data were analyzed with a statistical software package- Statistical Package for Social Sciences (SPSS, version 16.0 for Windows).

\section{RESULTS}

In the case group uterine artery Doppler value, both single uterine artery Doppler and average uterine Doppler $>2.3$ was considered as abnormal. Both the control and case groups were followed up throughout the gestation for the development of adverse pregnancy outcomes such as PE, gestational hypertension (GHTN), eclampsia, intrauterine growth restriction (IUGR), and oligohydramnios.

Out of 150 patients studied, $43 \%$ were between 21-25 years of age in both the groups, $39 \%$ and $36 \%$ were between 26 and 30. There are no significant differences between the groups $(p>0.05)$. The distribution of antenatal mean age of both the groups had 25.2 \pm 3.48 and $26.13 \pm 3.91$. There is no significant difference between the groups $(\mathrm{p}>0.05)$. Of the age group distribution, the youngest one is 18 years and the eldest woman is 39 years. In 150 women in the study, maximum women i.e. $54 \%$ are primigravida, youngest primi being 18 years and eldest primi is 35 years old. $46 \%$ are multi, youngest multi is 21 years and the eldest multi is 39 years old. About $7 \%$ and $19 \%$ of women in control and cases group having a significant family history of diabetes mellitus (DM) and hypertension (HTN) were included in this study. There is no significant family history of PE or eclampsia found in these groups. Family history is insignificant in my study group for adverse pregnancy outcomes (Table 1).

The medical history of the study population is shown in the table below. History of other medical disorders such as overt hypothyroidism, type 2 diabetes mellitus (DM), gestational diabetes mellitus (GDM) on diet/oral hypoglycaemic agents (OHA) and chronic hypertension is included. In the case group, 1 patient with a history of chronic hypertension present. There is no significant difference in the case and control group with a medical history. In the study group $3 \%$ history of $\mathrm{BOH}$ present. In the case group, $5 \%$ has $\mathrm{BOH}$ due to 2 neonatal death and 2 term IUD (Table 2).

Doppler clinical variables in the study group in shown in Table 3. The mean average of both right and left uterine Doppler in the control group is 1.42 with its minimum of 0.64 and a maximum of 2.02. In the case group with a mean average of 2.3 with its minimum of 2.3 and a maximum of $4.1 .1 \%$ in the control group was started on aspirin given age $>30$ years. In the case group, $31 \%$ were started on aspirin given average uterine artery PI more than 95th percentile $(>2.3)$ (Table 3 ). 
Table 1: Age wise distribution of study population.

\begin{tabular}{|c|c|c|c|c|c|c|c|c|}
\hline \multirow[t]{2}{*}{ Age } & \multirow[t]{2}{*}{ Mean } & \multirow{2}{*}{$\begin{array}{l}\text { Standard } \\
\text { deviation }\end{array}$} & \multirow{2}{*}{$\begin{array}{l}\text { Standard } \\
\text { error }\end{array}$} & \multicolumn{2}{|c|}{$\begin{array}{l}95 \% \text { confidence interval } \\
\text { for mean }\end{array}$} & \multirow[t]{2}{*}{ Minimum } & \multirow[t]{2}{*}{ Maximum } & \multirow[t]{2}{*}{ Significance } \\
\hline & & & & Lower & Upper & & & \\
\hline Control & 25.2 & 3.484 & 0.402 & 24.4 & 26 & 19 & 34 & \\
\hline Cases & 26.13 & 3.905 & 0.451 & 25.23 & 27.03 & 18 & 39 & $>0.05$ \\
\hline
\end{tabular}

Table 2: Medical history of the population in the study.

\begin{tabular}{|llll|}
\hline Medical disorders & Case & Control & Total \\
\hline Overt hypothyroidism & 3 & 2 & 5 \\
\hline Type II DM & 1 & 0 & 1 \\
\hline GDM on diet & 4 & 6 & 10 \\
\hline GDM on drugs & 5 & 2 & 7 \\
\hline Chronic hypertension & 1 & 0 & 1 \\
\hline Total & 14 & 10 & 24 \\
\hline Percentage & 19 & 13 & 16 \\
\hline Unaffected & 61 & 65 & 126 \\
\hline Percentage & 81 & 87 & 84 \\
\hline
\end{tabular}

Table 3: Uterine artery Doppler value ranges in both case and control group.

\begin{tabular}{|lllll|}
\hline $\begin{array}{l}\text { Uterine artery } \\
\text { Doppler }\end{array}$ & Control & $\%$ & Cases & $\%$ \\
\hline $\begin{array}{l}<\mathbf{1 . 4 9}(<\mathbf{5 0 t h} \\
\text { percentile) }\end{array}$ & 44 & 59 & 0 & 0 \\
\hline $\begin{array}{l}\mathbf{1 . 5 - 2 . 2 9}(>\mathbf{5 0 t h}- \\
\mathbf{9 5 t h} \text { percentile) }\end{array}$ & 31 & 41 & 0 & 0 \\
\hline $\begin{array}{l}\mathbf{2 . 3}(\geq \mathbf{9 5 t h} \\
\text { percentile) }\end{array}$ & 0 & 0 & 75 & 100 \\
\hline Total & 75 & & 75 & \\
\hline
\end{tabular}

Table 4 shows the association of 2 nd trimester Doppler with the study group. In the control group, 71 of had normal Dopplers, and 1 had bilateral uterine artery Doppler notching (B/L UA N+). Remaining 3 was quit after the 1st-trimester scan. In the case group, 65 of them had normal Doppler and 3 and 4 (total 7) had right and left uterine artery diastolic notching (RT-D N+ and LT-D N+). Out of 7/5 were started on prophylactic aspirin in the first trimester and 3 of them ended up in having PE. As compared to the control group, there is 2nd trimester Doppler abnormality in women who had their 1st trimester Doppler abnormality. Of which $50 \%$ of them ending up in adverse pregnancy outcomes.

Table 5 shows the third trimester Doppler abnormality was about $1 \%$ in control and 3\% in the case group. There is no significant difference in both the groups.

Table 6 shows association of IUGR in the study group. In the control group 5\% of them had IUGR and in the case group, $28 \%$ of them had IUGR. This shows that there is a significant outcome in the case group than the control group. There are significant cases of IUGR in the case group for both average and single uterine artery $\mathrm{PI} \geq 2.3$. Oligohydramnios in the study groups. In the control group, $7 \%$ of them had oligohydramnios and in the case group, $11 \%$ of them had oligohydramnios. There is no significant outcome between these groups.

Table 4: Association of 2nd trimester abnormality in both group.

\begin{tabular}{|lllll|}
\hline $\begin{array}{l}\text { 2nd trimester } \\
\text { Doppler }\end{array}$ & Control & $\%$ & Cases & $\%$ \\
\hline Normal & 71 & 95 & 65 & 87 \\
\hline RT-D N+ & 0 & 0 & 3 & 4 \\
\hline LT-D N + & 0 & 0 & 4 & 5 \\
\hline B/L UA N+ & 1 & 1 & 0 & 0 \\
\hline Quit & 3 & 4 & 3 & 4 \\
\hline Total & 75 & & 75 & \\
\hline
\end{tabular}

Table 5: Association of 3rd trimester Doppler abnormality in both group.

\begin{tabular}{|lllll|}
\hline $\begin{array}{l}\text { 3rd trimester - } \\
\text { Doppler }\end{array}$ & Control & $\%$ & Cases & $\%$ \\
\hline Normal & 68 & 91 & 67 & 89 \\
\hline Abnormal & 1 & 1 & 2 & 3 \\
\hline Quit & 6 & 8 & 6 & 8 \\
\hline Total & 75 & & 75 & \\
\hline
\end{tabular}

Table 6: Association of IUGR with study group.

\begin{tabular}{|lllll|}
\hline IUGR & Control & $\%$ & Cases & $\%$ \\
\hline Present & 4 & 5 & 21 & 28 \\
\hline Absent & 71 & 95 & 54 & 72 \\
\hline Total & 75 & & 75 & \\
\hline
\end{tabular}

Table 7 shows the association of gestational hypertension (GHTN) in the study groups. In the control group, $1 \%$, and the case group 5\% of them had GHTN. Out of 4, 3 had an average uterine artery Doppler more than 2.3 (maximum of 2.7) and 1 had single uterine artery Doppler abnormality. None of the 4 were started on prophylactic aspirin.

Table 7: Association of gestational hypertension with the study group.

\begin{tabular}{|lll|ll|}
\hline GHTN & Control & $\%$ & Cases & $\%$ \\
\hline Present & 1 & 1 & 4 & 5 \\
\hline Absent & 74 & 99 & 71 & 95 \\
\hline Total & 75 & & 75 & \\
\hline
\end{tabular}


Table 8 shows the association of PE in the study group. In the control group, none of them had PE. In the case group, $8 \%$ of them had PE. Out of 6,5 were started on prophylactic aspirin in the first trimester for abnormal Doppler and 1 was not started on aspirin. There is a significant outcome in the case group as compared to the control group. The role of aspirin in the prevention of PE was not effective. Out of 6,4 had average uterine artery $\mathrm{PI}>2.3$ and 2 had single uterine artery $\mathrm{PI}>2.3$.

Table 8: Association of PE in the study groups.

\begin{tabular}{|lllll|}
\hline PE & Control & $\%$ & Cases & $\%$ \\
\hline Present & 0 & 0 & 6 & 8 \\
\hline Absent & 75 & 100 & 69 & 92 \\
\hline Total & 75 & & 75 & \\
\hline
\end{tabular}

Table 9 shows the abnormal uterine artery Doppler in the study group and adverse pregnancy outcome. Out of 75 in the case group, single uterine artery Doppler abnormality was found in 42 and 33 are with average uterine artery Doppler $>2.3$. Both of them are associated with adverse pregnancy outcomes (average PI $>2.3$ is slightly more than single PI >2.3). In the case group the maximum percent of adverse pregnancy outcome is with IUGR-28\% and least percent for GHTN-5\% and $0 \%$ outcome with eclampsia. In the case group, $52 \%$ are associated with adverse pregnancy outcomes, but in the control group, only $19 \%$ were associated with adverse pregnancy outcomes. Adverse pregnancy outcome which was included is IUGR, Oligohydramnios, GHTN, pre-eclampsia, and eclampsia. So there is a significant outcome in the case group as compared to the control group. The p-value is highly significant.

Table 9: Abnormal uterine Doppler in the case group and adverse pregnancy outcome.

\begin{tabular}{|llllllll|}
\hline Clinical variables & Total & IUGR & Oligohydramnios & GHTN & PE & Eclampsia \\
\hline $\begin{array}{l}\text { Single uterine artery Doppler (right/left) } \\
\text { with its PI } \geq \mathbf{2 . 3}\end{array}$ & 42 & 10 & 3 & 1 & 2 & 0 \\
\hline Averageof right and left uterine artery & $56 \%$ & $13 \%$ & $4 \%$ & $1 \%$ & $3 \%$ & $0 \%$ \\
\hline $\begin{array}{l}\text { Doppler with its PI } \geq \mathbf{2 . 3} \\
\text { Total }\end{array}$ & 33 & 11 & 5 & 3 & 4 & 0 \\
\hline$(\%)$ & 75 & 21 & 8 & $4 \%$ & $5 \%$ & $0 \%$ \\
\hline
\end{tabular}

Table 10 shows 3 had preterm labour. The lowest gestational age in the case group at which the pregnancy terminated was 33 weeks for severe preeclampsia. Of the total study group, $9 \%$ of them have undergone elective csection for primigravida with breech presentation and repeat lower segment caesarean section (LSCS) with a history of previous LSCS, $23 \%$ have undergone emergency LSCS for obstetrical indications. 54\% delivered normally and $15 \%$ by vacuum-assisted delivery.

Table 10: Pregnancy terminated in case and control group $<37$ weeks.

\begin{tabular}{|lllll|}
\hline $\begin{array}{l}\text { Pregnancy } \\
\text { terminated }\end{array}$ & Case & $\%$ & Control & $\%$ \\
\hline Severe PE & 4 & 5 & 0 & 0 \\
\hline GHTN & 3 & 4 & 0 & 0 \\
\hline GHTN+IUGR & 1 & 1 & 0 & 0 \\
\hline $\begin{array}{l}\text { Severe } \\
\text { oligohydramnios }\end{array}$ & 1 & 1 & 2 & 3 \\
\hline Severe IUGR & 3 & 4 & 1 & 1 \\
\hline
\end{tabular}

\section{DISCUSSION}

Hypertensive disorders of pregnancy are one of the most common complications of pregnancy with an incidence of $5-10 \%$. The associated maternal morbidity, mortality, and neonatal complications are very adverse indicating the need for early identification of the condition preferably before the onset of clinical disease. A lot of research has been done and many screening options are identified for predicting the development of hypertensive disorders in pregnancy. But no single screening test is useful. ${ }^{12}$ Many studies done in the second trimester investigated the value of uterine artery Doppler in the prediction of the development of hypertensive disorders of pregnancy, scientific interest is now focused on the first trimester. This gives the opportunity of early intervention for modifying the severity of the disease and meticulous surveillance for early identification of the disease. ${ }^{13}$ In the study group, $1 \%$ in the control group and 5\% in the case group has $\mathrm{BOH}$ due to 2 neonatal death and 2 term IUD. Among them, none have developed a hypertensive disorder of pregnancy. In the study population, those who had abnormal uterine Doppler (>2.3) were started prophylactically on aspirin. $1 \%$ in the control group was started on aspirin given age $>30$ years. In the case group, $31 \%$ were started on aspirin given average uterine artery PI more than 95th percentile $(>2.3)$. Birth weight in the study was analyzed in both groups. These groups were categorized as very low birth weight $(<2 \mathrm{~kg})$, low birth weight $(2-2.5 \mathrm{~kg})$ and normal $(>2.5)$. In the control group, $5 \%$ of them had low birth weight and $95 \%$ had normal birth weight. In the case group, $7 \%$ had very low birth weight, $21 \%$ had low birth weight and $72 \%$ of them had normal birth weight. ${ }^{14}$ Of the total study group, $9 \%$ of them have undergone elective $\mathrm{c}$ - section for primigravida with breech presentation and repeat less with history of previous less, $23 \%$ of have undergone emergency LSCS for obstetrical indications. $54 \%$ delivered normally and $15 \%$ by vacuumassisted delivery. Age distribution and parity index were analyzed for association of adverse pregnancy in the case group. ${ }^{15}$ It is evident from the observation that most of the 
adverse pregnancy outcome is for the reproductive age group between 21-30 years and the adverse outcome was more for the primigravida in my study population. It is consistent with the study done by Khan et al $51 \%$ of primigravida developed hypertensive disorders of pregnancy. This shows that nulliparous women who are exposed to the paternal antigen for the first time are at increased risk of developing hypertensive disorders of pregnancy. ${ }^{16}$ In the prediction of $\mathrm{PE}$ significant contributions were provided by log MoM PI, ethnic origin, body mass index and previous and family history of PE. ${ }^{17}$ In the present study, abnormal uterine artery Doppler indices ( $>95$ th percentile) noted in 11-13 weeks and 6 days are compared for their predictive values in the development of adverse pregnancy outcome, such as the development of gestational hypertension, PE, eclampsia, IUGR and oligohydramnios in the study population and with the available studies which are a few in the first trimester. Abnormal Doppler value $>2.3$ ( $>95$ th percentile) is taken as cut off as a reference to this study. ${ }^{18}$ In the study conducted by O'Brien et al where 999 pregnant women were examined between 11 to 14 weeks during the routine scan using transvaginal color and pulsed Doppler. ${ }^{19}$ In the case group out of $75,56 \%$ of them had single uterine artery Doppler (SUAD) PI> and 44\% with average uterine artery Doppler (AUAD) PI $>2.3$. Out of $56 \%$ in SUAD $38 \%$ had an adverse pregnancy outcome and out of $44 \%$ with AUAD $69.6 \%$ had an adverse pregnancy outcome. In both the groups, the maximum adverse outcome was with IUGR. The control group has a $19 \%$ adverse pregnancy outcome, $6 \%$ for IUGR, $7 \%$ for oligohydramnios, $1 \%$ for GHTN, and $0 \%$ for PE. The case group has $52 \%$ of them had adverse pregnancy outcomes, $28 \%$ for IUGR, $11 \%$ for oligohydramnios, 5\% for GHTN, $8 \%$ for PE. P-value is highly significant $(<0.001)$ with the case group as compared to the control group for adverse pregnancy outcomes. ${ }^{20}$ Close monitoring of these patients results in early diagnosis, thus it reduces both maternal and perinatal mortality and morbidity. Thus above finding suggest that adding first-trimester uterine artery Doppler to NT scan has a great advantage in predicting adverse pregnancy outcome.

\section{CONCLUSION}

Over 12 months, antenatal mothers coming to the outpatient department (OPD) at PSG IMSR were screened for abnormal uterine artery Doppler and those who had abnormal Dopplers were closely monitored for the development of adverse pregnancy outcomes. This early identification of high-risk women can be helpful for us to start them with prophylactic aspirin which may help in modifying disease severity and time of disease occurrence. The study showed that first-trimester uterine artery Doppler with single and average uterine artery PI >95th centile (2.3) has a better screening value in my population. The overall performance of the first-trimester uterine artery Doppler in the prediction of adverse pregnancy outcomes is valuable. By identifying the high-risk women who have high predictive value for the development of adverse pregnancy outcome are closely monitored. Thus it has reduced the incidence of maternal and perinatal morbidity and mortality. To conclude from the present study, first trimester Doppler ultrasound is the best noninvasive investigation to assess changes in uteroplacental hemodynamics which help in early prediction of development of hypertensive disorders in pregnancy along with maternal characteristics which help in the early prophylactic intervention.

\section{Funding: No funding sources}

Conflict of interest: None declared

Ethical approval: The study was approved by the Institutional Ethics Committee

\section{REFERENCES}

1. Adelusi B, Ojengbede OA. Reproductive performance after eclampsia. Int J Gynaecol Obstet. 2016;24:1839.

2. Alessia M, Sahina C, Alessandro C. Hypertensive disorders of pregnancy. J Prenat Med. 2009;3(1):1-5.

3. Bainbridge SA, Sidle EH, Smith GN. Direct placental effects of cigarette smoke protect women from preeclampsia: the specific roles of carbon monoxide and antioxidant systems in the placenta. Med Hypotheses. 2005;64:17-27.

4. Barton J, Sibai B. Prediction and prevention of recurrent preeclampsia. Obstet Gynecol. 2008;112(2):359-72.

5. Berg CJ, Harper MA, Atkinson SM, Bell EA, Brown HL, Hage ML, et al. Preventability of pregnancyrelated deaths: results of a state-wide review. Obstet Gynecol. 2005;106:1228-34.

6. Buchbinder A, Sibai BM, Caritis S, Macpherson C, Hauth J, Lindheimer MD, et al. Adverse perinatal outcomes are significantly higher in severe gestational hypertension than in mild preeclampsia. Am J Obstet Gynecol. 2002;186(1):66-71.

7. Crispi F, Dominguez C, Llurba E, Martin-Gallan P, Cabero L, Gratacos E. Placental angiogenic growth factors and uterine artery Doppler findings for characterization of different subsets in preeclampsia and isolated intrauterine growth restriction. Am J Obstet Gynecol. 2006;195:201-7.

8. Dildy GA, Belfort MA, Smulian JC. Preeclampsia recurrence and prevention. Semin Perinatol. 2007;31(3):135-41.

9. Duckitt K, Harrington D. Risk factors for preeclampsia at antenatal booking: Systemic review of controlled studies. BMJ. 2005;330(7491):565.

10. Furuya M, Ishida J, Aoki I, Fukamizu A. Pathophysiology of placentation abnormalities in pregnancy-induced hypertension. Vasc Health Risk Manag. 2008;4(6):1301-13.

11. Gardosi J, Kady SM, McGeown P, Francis A, Tonks A. Classification of stillbirth by relevant condition at death (ReCoDe): a population-based cohort study. BMJ. 2005;331:1113-7. 
12. Goldenberg RL, Mercer BM, Moawad A, Thom E, Meis PJ, et al. The Preterm Prediction Study: recurrence risk of spontaneous preterm birth. National Institute of Child Health and Human Development Maternal-Fetal Medicine Units Network. Am J Obstet Gynecol. 1998;178(5):1035-40.

13. Hauth JC, Ewell MG, Levine RJ, Esterlitz JR, Sibai B, Curet LB, et al. Pregnancy outcomes in healthy nulliparas who developed hypertension. Calcium for Preeclampsia Prevention Study Group. Obstet Gynecol. 2000;95(1):24-8.

14. Hutcheon JA, Lisonkova S, Joseph KS. Epidemiology of pre-eclampsia and the other hypertensive disorders of pregnancy. Best Pract Res Clin Obstet Gynecol. 2011;25(4):391-403.

15. Kassebaum NJ, Bertozzi-Villa A, Coggeshall MS, Shackelford KA, Steiner C, Heuton KR, et al. Global and regional and national levels and causes of maternal mortality during 1990-2013: a systemic analysis for the global burden of disease study 2013. Lancet. 2014:384:980-1004.

16. Khan KS, Wojdyla D, Say L, Gülmezoglu AM, Van Look PF. WHO analysis of causes of maternal death: a systematic review. Lancet. 2006;367:1066-74.
17. Mc Donald SD, Best C, Lam K. The recurrence risk of severe de novo pre-eclampsia in singleton pregnancies: a population-based cohort. BJOG. 2009;116(12):1578.

18. Costello D, Kallogjeri D, Tungsiripat R, Leet T. Recurrence of preeclampsia: effects of gestational age at delivery of the first pregnancy, body mass index, paternity, and the interval between births. Am J Obstet Gynecol. 2008;199:55.

19. O'Brien TE, Ray JG, Chan WS. Maternal body mass index and the risk of pre-eclampsia: a systemic overview. Epidemiology. 2003;14(3):368-74.

20. Prakash J, Pandey LK, Singh AK, Kar B. Hypertension in pregnancy: a hospital-based study. J Assoc Physicians India. 2006;54:273-8.

Cite this article as: Bindu S. Uterine artery Doppler in first trimester in prediction of adverse pregnancy outcome in Dharmapuri district of Tamil Nadu. Int J Reprod Contracept Obstet Gynecol 2020;9:4268-73. 